\title{
Using Horn's Parallel Analysis Method in Exploratory Factor Analysis for Determining the Number of Factors
}

\author{
Ömay Çokluk ${ }^{1}$ \\ Ankara University
}

\author{
Duygu Koçak ${ }^{2}$ \\ Adryaman University
}

\begin{abstract}
In this study, the number of factors obtained from parallel analysis, a method used for determining the number of factors in exploratory factor analysis, was compared to that of the factors obtained from eigenvalue and scree plot-two traditional methods for determining the number of factors-in terms of consistency. Parallel analysis is based on random data generation, which is parallel to the actual data set, using the Monte Carlo Simulation Technique to determine the number of factors and the comparison of eigenvalues of those two data sets. In the study, the actual data employed for factor analysis was gathered from a total of 190 primary school teachers using the Organizational Trust Scale to explore a teacher's views about organizational trust in primary schools within the scope of another study. The Organizational Trust Scale comprises 22 items under the three factors of "Trust in Leaders," "Trust in Colleagues," and "Trust in Shareholders." A simulative data set with a sample size of 190 and 22 items was simulated in addition to the actual data through an SPSS syntax. The two data sets underwent parallel analysis with the iteration number of 1000 . The number of factors was found to be three. This was consistent with the number of factors obtained in the development process of the scale. The number of factors was restricted to three and exploratory factor analysis was re-performed on the actual data. It was concluded that the item-factor distributions obtained as a result of the analyses were consistent with those obtained in the scale development study. Hence, parallel analysis was found to provide consistent results with the construct obtained in the scale development study.
\end{abstract}

\section{Keywords}

Construct validity $\bullet$ Parallel analysis $\bullet$ Exploratory factor analysis $\bullet$ Number of factors $\bullet$ The Monte Carlo Simulation Technique

\footnotetext{
1 Correspondence to: Ömay Çokluk (PhD), Department of Measurement and Evaluation, Faculty of Educational Sciences, Ankara University, Cebeci, Ankara 06590 Turkey. Email address: cokluk@education.ankara.edu.tr

2 Department of Measurement and Evaluation, Adıyaman University, Adıyaman Turkey. Email address: dkocak@adıyaman.edu.tr Citation: Çokluk, Ö., \& Koçak, D. (2016). Using Horn's parallel analysis method in exploratory factor analysis for determining the number of factors. Educational Sciences: Theory \& Practice, 16, 537-551.
} 
Psychological characteristics are of an abstract or latent nature rather than a tangible, observable one and they are called constructs or factors (Kline, 2005; Nunnaly \& Bernstein, 1994). Constructs are hypothetical concepts and the existence of certain constructs is never absolutely confirmed. Therefore, observations of individual behavior mostly provide conclusions about psychological constructs. These psychological constructs such as intelligence, creativity, extrovertedness and introvertedness are not directly observable (Croker \& Algina, 1986). Cronbach and Meehl (1955) define psychological construct as "some postulated attribute of people" (as cited in Baykul, 2000). All constructs have two main features: 1. Every construct is an abstract summary of natural order; 2 . Constructs are associated with observable entities or phenomena (Murphy \& Davidshofer, 2001).

According to Lord and Novick (1968), constructs that are not directly observable can be defined in two different ways: operational definition, which is essential to measure those constructs; and the theoretical relationship between a given construct and others and the relationship between a given construct and criteria in the outer world in addition to the operational definitions (Crocker \& Algina, 1986). Operational definitions of constructs could relate to construct validity studies that discuss the development of a suitable measuring instrument for a construct and to what extent the instrument measures the related construct.

Construct validity is based on the analysis of the relationships between responses to test items. To some extent, the process of establishing construct validity for a given test is the development of a scientific theory (Tekin, 2000). Construct validity is associated with the validity of implications about non-observable variables through observable variables. Construct validity shows how accurately a measuring instrument measures abstract psychological characteristics. Measuring the related abstract construct is based on transformation of the construct into a tangible, observable entity through observable behaviors. The transformation process into an observable construct includes the following stages: determining behaviors related to the measured construct, revealing constructs that are relevant or irrelevant to the measured construct and showing behavioral patterns that express others related to the measured construct (Murphy \& Davidshofer, 2001).

Construct validity studies could be conducted with different methods according to the quality and the form of a given construct and those of the measuring instrument used to measure the related construct, whether there are theories and scientific research on the construct and some other features (Erkuş, 2003). Factor analysis is the most widely used method among these. In the literature, there is scientific consensus on the fact that factor analysis is a common statistical method used to determine construct validity (Anastasi, 1986; Atılgan, Kan, \& Doğan, 2006; Crocer 
\& Algina, 1986; Cronbach, 1990; Dancey \& Reidy, 2004; Erkuş, 2003; Pedhazur \& Pedhazur, Schmelkin, 1991; Urbina, 2004). Because of the advantage entailed by internal dependencies in constructs by nature, factor analysis reduces the complexity of data and thus provides nearly the same amount of information as extensive data obtained by a number of original observations, with only a few factors (Çokluk, Şekercioğlu, \& Büyüköztürk, 2010).

According to Floyd and Widaman (1995), factor analysis has two approaches in the evaluation of psychological constructs: exploration and variable reduction. The exploratory aim of factor analysis defines lower dimensions of measuring instruments that represent a given construct, on the basis of the theoretical structure from which the instruments have been developed. Accordingly, the analysis focuses on the exploration of latent variables that form the basis of a scale. Variable reduction in factor analysis is associated with obtaining the number of indicators, which could be considered as a summary, with the maximum variability and reliability in an extensive set of variables.

Depending on the aim, factor analysis could be classified as exploratory and confirmatory factor analysis. In exploratory factor analysis, there is a process of determining factors, with reference to the relationships between variables and developing a theory; whereas a pre-defined hypothesis of intervariable relationships is tested in confirmatory factor analysis (Kline, 1994; Stevens, 1996; Tabachnick \& Fidell, 2001).

The most critical, top priority stage of the analysis is "deciding the number of factors," although there are certain considerations in exploratory factor analysis performance (variance ratios explained by factors, factor loadings of items, items with high factor loadings more than one factor, and so on) (Fabrigar, Wegener, MacCallum, \& Strahan, 2009; Hayton, Allen, \& Scarpello, 2004; Henson \& Roberts, 2006; O’Connor, 2000; Fava \& Velicer, 1992; Zwick \& Velicer, 1986). Deciding the number of factors is far more important than other decisions, such as selection of analytical method and the type of rotation, because the power of exploratory factor analysis depends on the ability to discriminate significant factors from others. Thus, it is vital to determine the precise balance between correlations. Also, determining the number of factors needs close attention because more or fewer factors than necessary will lead to serious errors that affect results (Comrey \& Lee, 1992; Gorsuch, 1983; Harman, 1976).

There have been many recommended approaches in determining the number of factors since Spearman developed the factor analysis method. The following two are the most widely known: determining factors as significant with an eigenvalue greater than 1 (also known as the Kaiser-Guttmanrule) and examining the scree plot (Fabrigar et al., 1999; Ford, MacCallum, \& Tait, 1986; Wang \& Weng, 2002; Weng, 1995). However, methods for determining the number of factors are not restricted to those. 
"Parallel analysis," suggested by Horn (1965) is another approach to determine the number of factors, and a number of studies in the literature show this method to give good results (Reilly \& Eaves, 2000; Sarff, 1997; Velicer, Eaton, \& Fava, 2000; Wang, 2001; Zwick \& Velicer, 1986). It is seen that parallel analysis has become widely used over the recent years, with the development of user-friendly software, although it is not included in the most frequently used programs such as SPSS and SAS (Enzmann, 1997; Kaufman \& Dunlap, 2000; Lautenschlager, 1989; Longman, Cota, Holden, \& Fekken, 1989; O'Connor, 2000; Thompson \& Daniel, 1996). In the follow up process of Horn's research (1965), studies conducted by Humphreys and Ilgen (1969) and Humphreys and Montanelli (1975) have shown that the parallel analysis method is effective in determining the number of factors. Various methods such as regression methods, interpolation tables and the mean eigenvalues have also been developed to make parallel analysis performance easier (Allen \& Hubbard, 1986; Keeling, 2000; Lautenschlager, 1989; Lautenschlager, Lance, \& Flaherty, 1989; Longman et al., 1989; Montanelli \& Humphreys, 1976).

Parallel analysis is based on random data simulation to determine the number of factors. Using the Monte Carlo Simulation Technique, a random simulative (artificial) data set is generated besides the actual (real) data set and the estimated eigenvalues are calculated. When the method is employed, the number of factors where the eigenvalue in the simulative sample is higher than that of the actual data is considered significant (Ledesma \& Mora, 2007).

Parallel analysis (Horn, 1965) is a sample matrix based adaptation of the K1 method, in which factors with eigenvalues greater than 1 are considered significant, on the basis of the correlation matrix of the population. In the K1 method, the sum of squared values of (factor loadings) correlation coefficients between a factor and a number of variables is called eigenvalue and factors with eigenvalues greater than 1 are considered significant. Cliff (1988) states that the method is affected by the sampling error and it tends to result in a great (excessive) number of factors when applied to the sample matrix. The method is extensively used because it is userfriendly and it is merely applied to the correlation matrix of the population. The method tends to determine an excessive number of factors as sampling error is added as a rank to the correlation matrix in restricted samples (Gorsuch, 1983). Horn (1965) suggests that Eigen values of a given correlation matrix of a population-scale $p$ number of variables could be 1 but the initial eigenvalues in simulative samples are equal to 1 , and the following eigenvalues could be lower than 1 because sampling error is added to the matrix. Therefore, components or factors with greater eigenvalues, when compared to the simulative matrix besides the actual data are considered significant (Zwick \& Velicer, 1986). If an $\mathrm{m}$ data set with a magnitude of $\mathrm{N}$ is randomly extracted from a population of a normal distribution and $\mathrm{m}$ variables are correlated, an mxm 
correlation matrix is expected to be close to a unit matrix. Sampling theory points out that such a proximity between a correlation matrix and a unit matrix is a function of $\mathrm{m}$ and $\mathrm{N}$. Also, the theory stipulates that the average correlation equals 0 and variance of correlation is inversely correlated with sample size. Eigen values of a correlation matrix could be considered as the variance of the variables independently extracted from m variable (Horn, 1965).

Horn (1965) states that the effects of sampling error on eigenvalues of correlation matrices must be of concern while determining the number of factors in the eigenvalue greater than 1 method, as it leads to determining an excessive number of factors when samples are used that are restricted in number (smaller samples). Thus, it is advisable that correlation matrices obtained from randomly chosen data should be compared to those in the actual data. The mean eigenvalues of correlation matrices obtained from randomly chosen data sets include and reflect the effects of a given sampling error (Wengand \& Cheng, 2005).As parallel analysis sometimes tends to give an excessive number of factors, it is emphasized that the Type I error could decrease $(\alpha)$ by keeping eigenvalues obtained from simulative data at a confidence interval of.05, and thus, results would be more accurate this way (Buja \& Eyüboğlu, 1992; Glorferd, 1995; Harshman \& Reddon, 1983). Some researchers suggest that parallel analysis should be incorporated with a scree plot (Fabrigar et al., 1999; Ford et al., 1986). Horn (1965) asserts that iteration in data must be at a reasonable value although there is no strict rule about the number of iterated data sets used to calculate the mean eigenvalues. To some researchers, this number is 500-1000 (Hayton et al., 2004), but there are studies that have shown no significant difference between 1 and 100 (Crawford \& Koopman, 1979).

Silverstein (1977; 1987) compared the K1 method and the parallel analysis method in 24 data sets, and parallel analysis was found to give better results. Zwick and Velicer (1986) compared five methods employed in factor determining (parallel analysis, the minimum average partial correlation method, the scree plot, Bartlett's Chi-Square Test, eigenvalue greater than 1) under different conditions such as sample size, the number of variables and components, factorial saturation, the number of variables per component and single and complex variables etc., and concluded that parallel analysis was consistent with the actual data set used to determine the number of factors, with $92 \%$ accuracy.

Humphreys and Montanelli (1975) compared the parallel analysis method to the maximum likelihood method, and parallel analysis was found to give results that were consistent (almost 100\%) with the number of factors obtained from the actual data set. Dinno $(2009 ; 2010)$ examined the consistency of the parallel analysis method with the number of factors obtained from the actual data set for both factor 
analysis and principal components analysis, by changing distribution properties of the simulative data in the parallel analysis method and concluded that the methods were independent of the distribution (distribution-free) properties of data, and that for determining number of factors, parallel analysis was found to give results that were consistent with the number of factors obtained from the actual data set.

Crawford et al. (2010) compared the parallel analysis method, the principal components and principal factor methods and the criteria for the mean Eigen value to those of an eigenvalue of $95 \%$. As a result of the analyses, it was concluded that the accuracy percentage of the criterion for the eigenvalue of $95 \%$ depended on the item number per factor and gave the most accurate results in finding the initial eigenvalue. For the resulting eigenvalues, principal components analysis was found to give better results than principal factor analysis in the case of a single factor or a low correlation between factors. Factor analysis, based on the mean eigenvalue criterion, was found to give better results in multi-factor models in which the correlation between factors was high and the factor constructs were robust.

As is clear from the above-mentioned discussions, studies have shown that parallel analysis is an effective method for determining the number of factors. Despite being the most critical, top priority issue of factor analysis, determining the number of factors has been considered as one of the most challenging stages; this is particularly true for researchers inexperienced in factor analysis, although it is occasionally difficult for many experienced researchers, depending on the characteristics of the instrument (or scale), the research group and thus the collected data. This emphasizes the need for further empirical evidence to support the accuracy of the decisions about the number of factors. To this end, the research problem is parallel analysis of the number of factors obtained from the actual and the simulative data set and examining the consistency of the resulting numbers of factors.

\section{Method}

The study aims to compare the numbers of factors obtained from the parallel analysis method, a method in exploratory factor analysis for determining the number of factors to those from the eigenvalue and the scree plot graphic methods, which are traditional methods for determining the number of factors and examine their consistency. In this section, the measuring instrument and the simulative data set are mentioned.

\section{Instrument}

The "Organizational Trust Scale," developed by Y1lmaz (2005), was used in the study to determine the number of factors. The Organizational Trust Scale consists of 22 items under three factors: "Trust in Leaders," "Trust in Colleagues," and "Trust 
in Shareholders." The first factor consists of seven items and the Cronbach-alpha reliability coefficient is $\alpha=.89$. The second factor consists of eight items and the Cronbach-alpha reliability coefficient is $\alpha=.87$. The third factor consists of seven items and the Cronbach-alpha reliability coefficient is $\alpha=82$. The total variance explained by the whole scale is $45.31 \%$ and the Cronbach-alpha reliability coefficient is $\alpha=.92$ (Y1lmaz, 2006).

\section{Data Simulation}

The research used the data collected from a total of 190 primary school teachers in the scope of a study by Çokluk and Y1lmaz (2008) to explore primary school teachers' views about organizational trust, using the Organizational Trust Scale. A data set was simulated through a syntax written in SPSS besides the actual data, with a sample size of 190 and the item number of 22. The process was arranged with the iteration number of 1000 and the two data sets underwent parallel analysis.

\section{Findings}

In this section, the results of the parallel analysis of the actual data set and the simulative (artificial) data set are mentioned.

Parallel analysis, suggested by Horn (1965) as a method to determine the number of factors, is based on the comparison of eigenvalues of the actual data to those of the simulative data. In parallel analysis, eigenvalues of the determined factors in randomly simulated data set are compared to those of the factors in the actual data set. In this process, the focal point is how many of the factors obtained from the actual data have an eigenvalue greater than that of the simulative data and accordingly the number of factors is decided. The number of factors at the point where the eigenvalue in the simulative data is greater than that of the actual data is considered significant (Uyar, 2012). All studies (Gorsuch, 1983; Horn, 1965; Linn 1968; Revelle, 2007; Zwick \& Linn, 1986) that compared a number of factor determination methods specified that the parallel analysis method performs accurate estimations in determining number of factors, and also eigenvalue and scree plot methods tend to ascertain on overdetermining the number of factors.

In the study, exploratory factor analysis was applied to the Organizational Trust Scale in order to show how parallel analysis was employed to determine the number of factors. To this end, the results of Kaiser-Meyer-Olkin (KMO) values and Bartlett's Test of Sphericity were examined to test the eligibility of the Organizational Trust Scale in factor extraction. $\mathrm{KMO}=0.899$ and Bartlett's Test of Sphericity were found significant $\left[\mathrm{c}^{2}=2576.085, p<.01\right]$. The findings showed that factor analysis could be performed on the Organizational Trust Scale. The actual data and the simulative 
data underwent parallel analysis through a syntax written in SPSS. Results of the exploratory factor analysis is presented in Table 1 .

Table 1

Percentages of Eigen Value, Explained Variance and Cumulative Variance as a Result of the Factor Analysis

\begin{tabular}{cccc}
\hline Factor & Eigenvalue (\%) & Explained variance (\%) & Cumulative variance (\%) \\
\hline 1 & 8.890 & 38.651 & 38.651 \\
2 & 2.552 & 11.098 & 49.749 \\
3 & 1.680 & 7.304 & 57.053 \\
4 & 1.148 & 4.991 & 62.044 \\
5 & 0.986 & 4.287 & 66.331 \\
\hline
\end{tabular}

When Table 1 is examined, the eigenvalues' methods according to four factors seem to set out a structure. Exploratory factor analysis of the obtained scree plot is presented in Graphic 1.

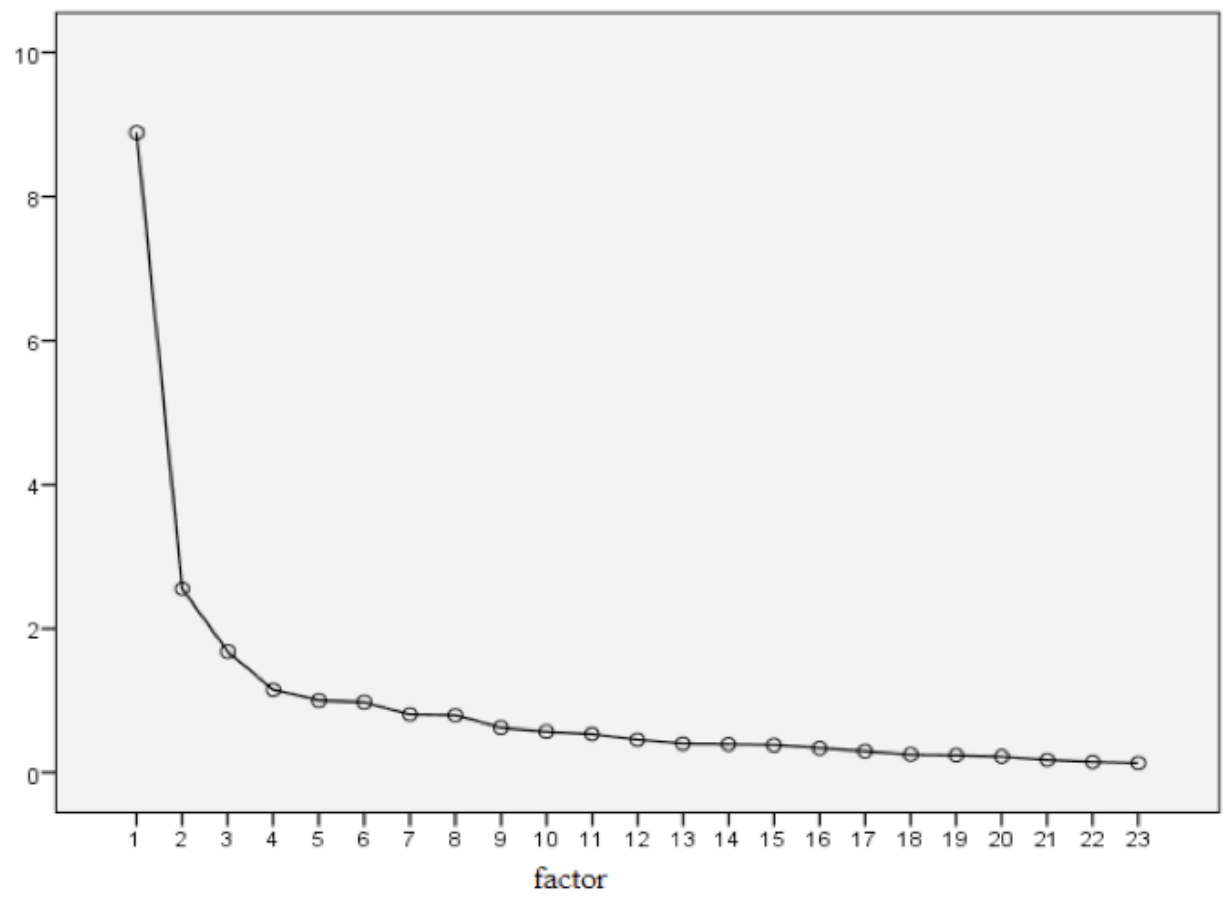

Graphic 1. The scree plot of the factor analysis.

The scree plot graphic shows that there is a four-factor solution, and the number of factors correspond to the number of factors determined via the eigenvalue methods. It is emphasized that generally these two methods conform to each other; however, they perform an over-determining number of factors (Ford et al., 1986; Hayton et al., 2004). 
Table 2

Eigen Values of the Actual Data and the Simulative Data

\begin{tabular}{ccc}
\hline Factor & Eigen values of the actual data & Eigen values of the simulative data \\
\hline 1 & 8.890 & 1.783 \\
2 & 2.540 & 1.629 \\
3 & 1.677 & 1.531 \\
4 & 1.064 & 1.441 \\
5 & 0.980 & 1.364 \\
\hline
\end{tabular}

As mentioned above, the intended use of parallel analysis provides further evidence or a basis to decide the number of factors more easily. When Table 1 is examined, it is seen that the eigenvalue of the first factor in the actual data is 8.890 , while it is 1.783 in the simulative data set. The eigenvalue of the second factor in the actual data is 2.540, whereas it is 1.629 in the simulative data. The eigenvalue of the third factor in the actual data is 1.677 , while it is 1.531 in the simulative data. When we shift from the third factor to the fourth, the case is different and thus the number of the scale factors is determinedly restricted to 3 because the eigenvalue of the simulative data of the fourth factor is higher than that of the actual data. The eigenvalue of the fourth factor in the actual data is 1.064 , whereas it is 1.44 in the simulative data. This case should be considered as the point at which parallel analysis introduces a decision about the number of factors.

It is likely to observe the number of factors decided with the support of parallel analysis in the same way as seen on the scree plot presented in Graphic 2.

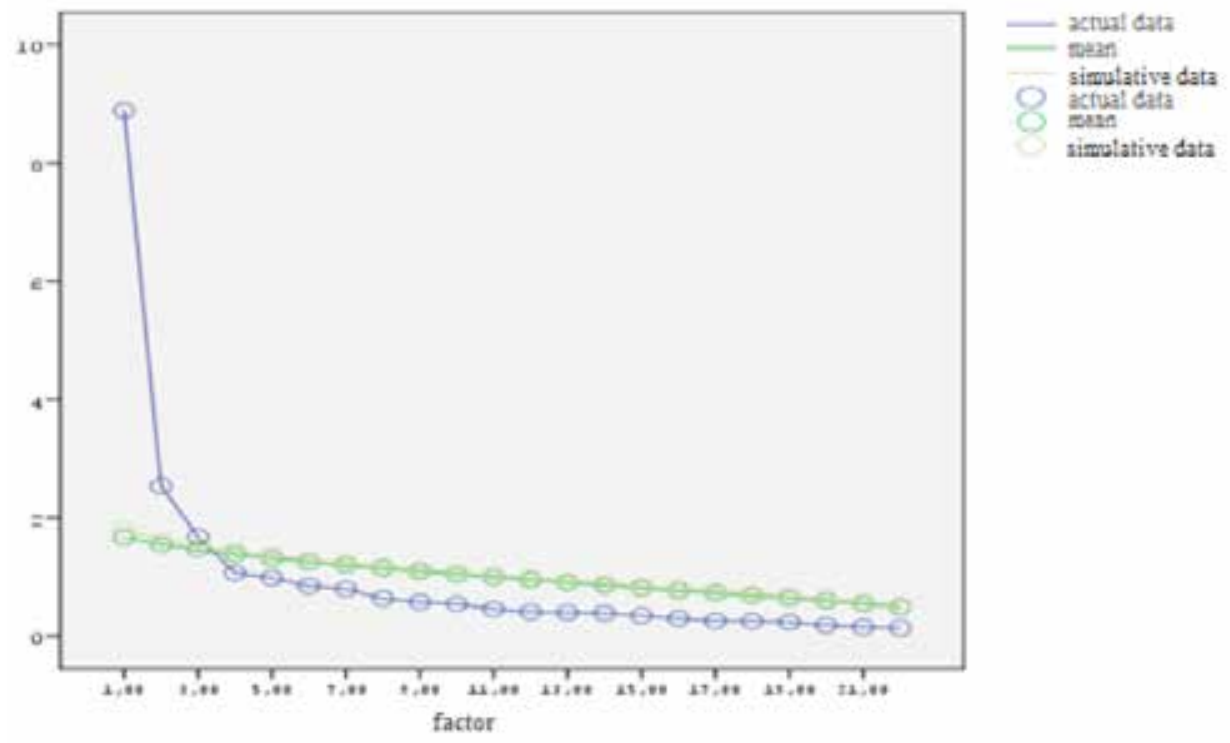

Graphic 2. The scree plot of the actual data and the simulative data. 
When the scree plot in Graphic 2, which presents the curves of the actual data along with the simulative data, is examined, it is obvious that the three-factor construct decided as a result of the examination of the eigenvalues is supported. In the graphic, it is seen that the first three factors of the actual data have higher eigenvalues than the first three factors of the simulative data and as of the third factor, the eigenvalues of the simulative data are greater.

The number of factors performed via the eigenvalue and scree plot methods do not correspond to the number of factors obtained from the scale development study, and the number of factors were found to be more than expected. In addition, the number of factors found via the parallel analysis method correspond to the number of factor obtained from the scale development study.

As a result of the above-mentioned observations, the number of the scale factors in the study was decided to be three and the analysis was re-performed on the actual data*, with that restricted number.

Table 3

Percentages of Eigen value, Explained Variance and Cumulative Variance as a Result of the Factor Analysis on the Actual Data

\begin{tabular}{cccc}
\hline Factor & Eigenvalue (\%) & Explained variance (\%) & Cumulative variance (\%) \\
\hline 1 & 8.890 & 40.408 & 40.408 \\
2 & 2.540 & 11.550 & 51.958 \\
3 & 1.677 & 7.625 & 59.583 \\
\hline
\end{tabular}

*It is not likely to run exploratory factor analysis on simulative data. That is why the presented results of exploratory factor analysis are of the actual data.

When Table 3 is examined, it is clearly seen that the total explained variance as a result of the re-performed exploratory factor analysis with a restricted number of factors to three is $59.583 \%$. Results of the exploratory factor analysis of the Organizational Trust Scale are presented in Table 4.

\begin{tabular}{|c|c|c|c|c|c|}
\hline $\begin{array}{l}\text { Table } \\
\text { Facto }\end{array}$ & nalysis Results of the $\mathrm{Or}$ & nizatio & Trust Scale & & \\
\hline & Factor 1 & & Factor 2 & & Factor 3 \\
\hline Item & Rotated factor loading & Item & Rotated factor loading & Item & Rotated factor loading \\
\hline 1 & 0.866 & 20 & 0.753 & 16 & 0.724 \\
\hline 15 & 0.859 & 4 & 0.744 & 7 & 0.723 \\
\hline 5 & 0.825 & 3 & 0.710 & 22 & 0.720 \\
\hline 12 & 0.820 & 18 & 0.677 & 8 & 0.711 \\
\hline 9 & 0.784 & 11 & 0.671 & 2 & 0.687 \\
\hline 10 & 0.782 & 19 & 0.664 & 6 & 0.578 \\
\hline 17 & 0.600 & 14 & 0.617 & 13 & 0.532 \\
\hline & & & & 21 & 0.480 \\
\hline
\end{tabular}


When Table 4is examined, as a result of the varimax rotation, the first factor consists of items 1, 15, 5, 12, 9, 10 and 17; the second factor consists of items 20, 4, $3,18,11,19$ and 14; and the third factor consists of items 16, 7, 22, 8, 2, 6, 13 and 21. It is also clear that the rotated factor loadings in the first factor range from 0.600 to 0.866 ; those in the second factor range from 0.617 to 0.753 and the rotated factor loadings of the items in the third factor range from 0.480 to 0.724 .

It has been concluded that the results of the exploratory factor analysis are consistent with those obtained in the scale development study by Y1lmaz (2006). In other words, the results of the study overlap with the item-factor distribution defined in the original scale development study. When the validity and reliability study of the Organizational Trust Scale is examined, it is seen that the scale consists of three factors and they are respectively named "Trust in Leaders," "Trust in Shareholders" and "Trust in Colleagues." All these findings could be interpreted as indicators of consistent results of the parallel analysis method with the actual data in deciding the number of factors.

\section{Discussion}

This study attempted to give examples of the use of the parallel analysis method, one of the methods in factor analysis which is used to determine the number of factors. As determining the number of factors constitutes one of the most critical issues in exploratory factor analysis and there are occasional difficulties in the decision process, further empirical evidence to support such decisions could be needed. Hence, employing the parallel analysis method is considered to assist researchers and other practitioners in exploratory factor analysis applications.

Examinations within the scope of the research have shown that the parallel analysis method is found to have consistent results with the actual data set in determining the number of factors and the original scale. In other words, the parallel analysis method has been found to give good results in determining the accurate number of factors. The result is consistent with the other study findings in the literature. For example, in a study by Zwick and Velicer (1986), which compared the methods for determining the number of factors, it was concluded that the parallel analysis in any conditions was found to give the best results in the examinations of determining the number of factors under different circumstances. In a study by Humphreys and Montanelli (1975), which compared the effectiveness of the parallel analysis method and the maximum likelihood method in determining the number of factors, it was concluded that the parallel analysis method gave the number of factors with $100 \%$ accuracy. It could be suggested that the obtained result is supported by other researchers who examine the accuracy of the parallel analysis method in determining the number of factors under different circumstances (Buja \& Eyüboğlu, 1992; O’Connor, 2000; Piconne, 2009). 
As a result, it can be emphasized that the parallel analysis method is an eligible, consistent method in deciding the number of factors. It is advisable for researchers to examine results of the parallel analysis method in data sets to be simulated under conditions such as different sample sizes, different numbers of factors and items in terms of accuracy and consistency.

\section{References}

Allen, S. J., \& Hubbard, R. (1986). Regression equations for the latent roots of random data correlation matrices with unities on the diagonal. Multivariate Behavioral Research, 21(3), 393-398.

Anastasi, A. (1968). Psychological testing. London, UK: The Macmillian Company, New York Collier-Macmillan Limited.

Atılgan, H., Kan, A., \& Doğan N. (2006). Eğitimde ölçme ve değerlendirme [Measurement and evaluation in education]. Ankara, Turkey: Anı Yayıncılık.

Baykul, Y. (2000). Eğitimde ve psikolojide ölçme [Measurement and evaluation in education]. Ankara, Turkey: ÖSYM Yayınları.

Beauducel A. (2001). Problems with parallel analysis in datasets with oblique simple structure. Methods of Psychological Research Online, 6(2), 141-157.

Buja, A., \& Eyuboglu, N. (1992). Remarks on parallel analysis. Multivariate Behavioral Research, 27(4), 509-540.

Cliff, N. (1988). The eigenvalues-greater-than-one rule and the reliability of components. Psychological Bulletin, 103(2), 276-279.

Çokluk, Ö., \& Yılmaz, K. (2008). İlköğretim okullarında örgütsel güven hakkında öğretmen görüşleri [Views of primary school teachers about organizational trust]. Kuram ve Uygulamada Eğitim Yönetimi, 54, 211-233.

Çokluk, Ö., Şekercioğlu, G., \& Büyüköztürk, Ş. (2010). Sosyal bilimler için çok değişkenli istatistik SPSS ve Lisrel uygulamalart [Multivariate statistics in social sciences: SPSS and Lisrel application]. Ankara, Turkey: PegemAkademi.

Comrey, A. L., \& Lee, H. B. (1973). A first course in factor analysis. New York, NY: Academic Press.

Comrey, A. L., \& Lee, H. B. (1992). A first course in factor analysis. Hillsdale, NJ: Lawrence Erlbaum.

Crawford, A. V., Green, B. S., Levy, R., Lo, W. J., Scott, L., Svetina, D., \& Thompson, M. S. (2010). Evaluation of parallel analysis methods for determining the number of factors. Educational and Psychological Measurements, 70(6), 885-901.

Crawford, C. B., \& Koopman, P. (1979).Inter-rater reliability of scree test and mean square ratio test of number of factors. Perceptual \& Motor Skills, 49, 223-226.

Crocker, L., \& Algina, J. (1986). Introduction to classical and modern test theory. Philadelphia, PA: Harcourt Brace Jovanovich College Publishers.

Cronbach, L. J. (I 990). Essentials of psychological testing. New York, NY: Harper CoIIins.

Dancey, C., \& Reidy, J. (2004). Statistics without maths for psychology: Using SPSS for Windows. London, UK: Prentice Hall. 
Dinno, A. (2009). Exploring the sensitivity of Horn's parallel analysis to the distributional form of random data. Multivariate Behavioral Research, 44, 362-388.

Dinno, A. (2010). Gently clarifying the application of Horn's parallel analysis to principal component analysis versus factor analysis. Retrieved from http://doyenne.com/Software/ files/PA_for_PCA_vs_FA.pdf

Enzmann, D. (1997). Ran Eigen: A program to determine the parallel analysis criterion for the number of principal components. Applied Psychological Measurement, 21, 232-233.

Erkuş, A. (2003). Psikometri üzerine yazılar [Essays on psychometry]. Ankara, Turkey: Türk Psikologlar Derneği Yayınları.

Fabrigar, L. R., Wegener, D. T., MacCallum, R. C., \& Strahan, E. J. (1999). Evaluating the use of exploratory factor analysis in psychological research. Psychological Methods, 4(3), 272-299.

Fava, J. L., \& Velicer, W. F. (1992).The effects of over extraction on factor and component analysis. Multivariate Behavioral Research, 27, 387-415.

Floyd, F. J., \& Widaman, K. F. (1995).Factor analysis in the development and refinement of clinical assessment instruments. Psychological Assessment, 7(3), 286-299.

Ford, J. K., MacCallum, R. C., \& Tait, M. (1986). The applications of exploratory factor analysis in applied psychology: A critical review and analysis. Personnel Psychology, 39, 291-314.

Glorfeld, L. W. (1995). An improvement on Horn's parallel analysis methodology for selecting the correct number of factors to retain. Educational and Psychological Measurements, 55, $377-393$.

Gorsuch, R. L. (1983). Factor analysis. Philadelphia, PA: Saunders.

Harman, H. H. (1967). Modern factor analysis. Chicago, IL. The University of Chicago Press.

Harshman, R. A., \& Reddon, J. R. (1983).Determining the number of factors by comparing real with random data: A serious flaw and some possible corrections. Proceedings of the Classification Society of North America at Philadelphia, 14-15.

Hayton, J. C., Allen, D. G., \& Scarpello, V. (2004). Factor retention decisions in exploratory factor analysis: A tutorial on parallel analysis. Organizational Research Methods, 7(2), 191-205.

Henson, R. K., \& Roberts, J. K. (2006). Use of exploratory factor analysis in published research: Common errors and some comment on improved practice. Educational and Psychological Measurement, 66(3), 393-416.

Horn, J. L. (1965). A rationale and test for the number of factors in factor analysis. Psychometrica, 30(2), 179-185.

Humphreys, L. G., \& Ilgen, D. (1969). Note on a criterion for the number of common factors. Educational and Psychological Measurement, 29, 571-578.

Humphreys, L. G., \& Montanelli, R. G. Jr. (1975).An investigation of the parallel analysis criteria on for determining the number of common factors. Multivariate Behavioral Research, 10, 193-205.

Kaufman, J. D., \& Dunlap, W. P. (2000).Determining the number of factors to retain: A Windows-based FORTRAN-IMSL program for parallel analysis. Behavior Research Methods, Instruments and Computers, 32, 389-395.

Keeling, K. B. (2000).A regression equation for determining the dimensionality of data. Multivariate Behavioral Research, 35, 457-468. 
Kline, P. (1994). An easy guide to factor analysis. New York, NY: Routledge.

Kline, R. B. (2005). Principles and practice of structural equation modeling. New York \& London: The Guilford Press.

Lautenschlager, G. J. (1989). A comparison of alternatives to conducting Monte Carlo analyses for determining parallel analysis criteria. Multivariate Behavioral Research, 24(3), 365-395.

Ledesma, D. R., \& Mora, P. V. (2007). Determining the number of factors to retain in EFA: An easy-to-use computer program for carrying out parallel analysis. Practica Assessment, Research\& Evaluation, 12(2), 1-11.

Longman, R. S., Cota, A. A., Holden, R. R., \& Fekken, G. C. (1989). A regression equation for the parallel analysis criterion in principal components analysis: Mean and $95^{\text {th }}$ percentile eigenvalues. Multivariate Behavioral Research, 24(1), 59-69.

Lord, F. M., \& Novick, M. R. (1968). Statistical theories of mental test scores. Reading, MA: Addison-Wesley.

Montanelli, R. G. Jr., \& Humphreys, L. G. (1976). Latent roots of random data correlation matrices with squared multiple correlations on the diagonal: A Monte Carlo study. Psychometrika, 41, 341-348.

Murphy, K. R., \& Davidshofer, C. O. (2001). Psychological testing. New Jersey, NJ: Prentice Hall.

Nunnally, J. C., \& Bernstein, I. H. (1994). Psychometric theory. New York, NY: McGraw-Hill.

O'Connor, B. P. (2000). SPSS and SAS programs for determining the number of components using parallel analysis and Velicer's MAP test. Behavior Research Methods, Instruments, and Computers, 32(3), 396-402.

Pedhazur, E., \& Schmelkin, L. P. (1991). Measurement, design and analysis: An in the grated approach. Hillsdale, NJ: Lawrence Erlbaum.

Reilly, A., \& Eaves, R. C. (2000). Factor analysis of the Minnesota Infant Development Inventory based on a Hispanic migrant population. Educational and Psychological Measurement, 60, 271-285.

Sarff, P. L. (1997). Using factor replicability to evaluate number of factors rules. Dissertation Abstracts International, Section B: The Sciences \& Engineering, 58(4-B), 2175.

Silverstein, A. B. (1977). Comparison of two criteria for determining the number of factors. Psychological Reports, 41, 387-390.

Silverstein, A. B. (1987). Note on the parallel analysis criterion for determining the number of common factor or principal components. Psychological Reports, 61, 351-354.

Stapleton, C. D. (1997, January). Basic concepts and procedures of confirmatory factor analysis. Paper Presented at the Annual Meeting of the Southwest Educational Research Association, Austin.

Stewens, J. (1996). Applied multivariate statistics for the social science. New Jersey, NJ: Lawrence Erlbaum Associates.

Tabachnick, B. G., \& Fidell, L. S. (2007). Using multivariate statistics. Boston, MA: Allyn \& Bacon.

Tekin, H. (2000). Eğitimde ölçme ve değerlendirme [Measurement and evaluation in education].Ankara, Turkey: Yargı Yayınevi.

Thompson, B., \& Daniel, L. G. (1996). Factor analytic evidence for the construct validity of scores: A historical overview and some guidelines. Educational and Psychological Measurement, 56(2), 197-208. 
Urbina S. (2004). Essentials of psychological testing. Hoboken, NJ: John Wiley \& Sons.

Uyar, S. (2012). Açımlayıcı faktör analizinde boyut sayısını belirlemede kullanılan yöntemlerin karşılaştırllması [A comparison of methods to determine the number of factor in explanatory factor analysis] (Master'sthesis, Hacettepe University, Ankara, Turkey). Retrieved from http:// tez2.yok.gov.tr/

Velicer, W. F., Eaton, C. A., \& Fava, J. L. (2000). Construct explication through factor or component analysis: A review and evaluation of alternative procedures for determining the number of factors or components. In R. D. Goffin \& E. Helmes (Eds.), Problems and solutions in human assessment (pp. 41-71). Dordrecht, MA: Kluwer Academic Publisher.

Wang, C.-N., \& Weng, L.-J. (2002). Evaluating the use of exploratory factor analysis in Taiwan: 1993-1999. Chinese Journal of Psychology, 44, 239-251.

Weng, L. J., \& Cheng, C. P. (2005). Parallel analysis with unidimensional binary data. Educational and Psychological Measurements, 75(5), 697-716.

Weng, L.-J. (1995). An overview of applications of factor analysis. In Social survey and analysis: The first interdisciplinary symposium on research methods in the social sciences (pp. 245-265). Taipei, Taiwan: Institute of Ethnology, Academia Sinica.

Yılmaz, E. (2005). Okullarda örgütsel güven ölçeğinin geçerlik ve güvenirlik çalışması [Validity and reliability of the organizational trust of school scale]. Selçuk Üniversitesi Sosyal Bilimler Dergisi, 14, 567-580.

Zwick, W. R., \& Velicer, W. F. (1986). Comparison of five rules for determining the number of components to retain. Psychological Bulletin, 99(3), 432-442. 
